\title{
Perancangan Sistem Informasi Aplikasi Kasir pada Kafe Restorasi Kopi Berbasis Web
}

\author{
Yoga Handoko Agustin ${ }^{1}$, Ayu Latifah ${ }^{2}$, Andi Fikri Nugraha ${ }^{3}$ \\ Jurnal Algoritma \\ Sekolah Tinggi Teknologi Garut \\ J1. Mayor Syamsu No. 1 Jayaraga Garut 44151 Indonesia \\ Email : jurnal@itg.ac.id \\ 1yoga.handoko@itg.ac.id \\ 2ayulatifah@itg.ac.id \\ 31706077@itg.ac.id
}

\begin{abstract}
Abstrak - Pertumbuhan usaha kafe yang begitu pesat di indonesia ini dengan banyaknya pengunjung, sehingga kafe mendapatkan kesulitan untuk memerhatikan orderan pesanan. Pengunjung menunggu terlalu lama untuk mendapatkan pesanan yang dipesan sehingga kurang adanya kenyamanan bagi pengunjung. Sistem informasi aplikasi kasir ini dirancang dalam proses pemesanan menu makanan dan minuman dengan berbasis website menggunakan kode respons cepat (QR) yang tujuannya untuk mwmbuat operasional kafe berjalan menjadi lebih cepat, aman, efektif, dan akurat. Metodologi yang digunakan yaitu Rational Unified Process, sebagai salah satu tahap pengembangan aplikasi dengan empat tahapan yang digunakan yaitu inception, elaboration, construction, dan transition dengan memakai pemodelan UML. Pada aplikasi sistem informasi kasir ini menghasilkan pengelolaan laporan penjualan kafe menjadi lebih baik karena adanya proses yang terkomputerisasi, maka data dapat tersimpan dengan aman. Sistem informasi ini memamkai database MySQL dan dikembangkan menggunakan bahasa pemrograman PHP.
\end{abstract}

Kata Kunci - Aplikasi Kasir; Kafe; Pemesanan Menu; QR Code; Rational Unified Process; Sistem Informasi.

\section{PENDAHULUAN}

Perkembangan tempat usaha yang semakin pesat pada saat ini meminta adanya perubahan sistem baru khususnya dalam pemesanan makanan di suatu kafe. Kafe merupakan suatu tempat di mana kita bisa membeli minuman dan makanan kecil yang buka hingga larut malam, pelayanan dengan lebih efektif akan menciptakan rasa nyaman dan puas yang diperoleh pelanggan maka akan memberikan kesan positif [1]. Dari banyaknya tempat usaha sejenis dan saling bersaing untuk mendapatkan keuntungan maka pemilik usaha harus lebih memperhatikan pelayanan kepada pelanggan. Hal yang dapat membuat pelanggan menjadi nyaman dan puas pada pelayanan yaitu menu yang di pesan dihidangkan dengan cepat. Pada saat pelanggan melakukan pesanan baru maupun pesanan tambahan, pelanggan ingin disajikan tanpa harus menunggu terlalu lama sesegera mungkin dan tanpa ada kesalahan.

Berdasarkan permasalahan tersebut, untuk meningkatkan efisiensi produksi pada industri kafe yang kompetitif, proses pemesanan menu menjadi perihal yang sangat penting. Bagaimana meningkatkan efisiensi dalam memberikan pelayanan menu kepada pelanggan, sehingga dapat memproduksi pelayanan dapur kafe dengan baik. Untuk mengatasi permasalahan tersebut menggunakan teknologi scan Qrcode, berupa gambar matriks dua dimensi yang berfungsi sebagai menyimpan data. Teknologi QR code dipilih karena menyediakan metode pengumpulan data yang cepat, mudah, nyaman, akurat, dan otomatis, dengan begitu mempermudah pengunjung memesan menu dan selaku pemilik usaha dapat memanajemen pesanan secara realtime [2] [3]. 
Pada penelitian ini terdapat beberapa jurnal yang berhubungan dengan permasalahannya, (1) berjudul "Pengembangan Aplikasi Kasir Pada Sistem Informasi Rumah Makan Padang Ariung" jurnal tersebut menghasilkan sebuah aplikasi kasir yang dapat memudahkan perhitungan dalam proses transaksi yang dilakukan sehingga dapat meminimalisir waktu perhitungan [4]. (2) berjudul "Sistem Informasi Penjualan Makanan Dan Minuman Di Wejie Kopi Berbasis Web" penelitian ini menghasilkan sebuah sistem di dalam pemesanan menu yang dilakukan oleh konsumen memakai web yang bertujuan agar konsumen bisa langsung melihat menu pada sebuah kafe [5]. (3) berjudul "Sistem Informasi Kasir di Hokky Waroeng Dimsum Surakarta" pada penelitian ini membangun sistem informasi kasir yang bertujuan untuk mempermudah kegiatan transaksi pelayanan terhadap pelanggan dan penyajian laporan penjualan yang akurat sehingga terhindar dari kesalahan dalam menghitung keuangan [6]. (4) berjudul "Sistem Informasi Kasir Berbasis Web Pada B-Food Bumiayu" pada penelitian ini menghasilkan aplikasi kasir berbasis web yang memiliki beberapa fitur yaitu perhitungan proses pembayaran, memudahkan pembuatan laporan secara berkala, mempercepat proses transaksi khususnya pada waktu terjadinya transaksi yang banyak sehingga menjadi lebih optimal dari suatu sistem yang sudah terkomputerisasi [7]. (5) berjudul "Pengembangan Aplikasi Penjualan Sparepart di Bengkel Anugrah Jaya Motor Berbasis Desktop" pada penelitian menghasilkan aplikasi penjualan sparepart berbasis desktop, yang berfokus pada transaksi penjualan, proses pembuatan laporan dan jumlah stok barang [8].

Dari kelima penelitian ini dirujuk untuk merancang aplikasi kasir berbasis web dalam melakukan pemesanan menu yang menggunakan QR Code di masing-masing meja kafe dan pelanggan dapat mengakses aplikasi tanpa harus registrasi sehingga dapat menarik minat para pelanggan untuk mengunjungi kafe tersebut. Bagi pemilik usaha dapat meningkatkan operasional sistem kasir secara terkomputerisasi dan untuk pelanggan dapat mempermudah proses pemesanan makanan dengan scan kode QR juga memberikan pengalaman baru bagi pelanggan atas pelayanan yang mereka peroleh

\section{METODOLOGI PENELITIAN}

Metodologi yang dipakai pada perancangan aplikasinya yaitu Rational Unified Process (RUP) Merupakan suatu pendekatan proses pengembangan terhadap perangkat lunak yang dikerjakan secara terus menerus, yang berfokus ke arsitekturnya, lebih di tunjukan juga berdasarkan penggunaan kasus [9], dan pemodelannya memakai Unified Modeling Language (UML). Tahapannya akan digambarkan pada diagram Work Breakdown Structure (WBS), berikut tahapan kerja pada perancangan Sistem Informasi Aplikasi Kasir Pada Kafe Restorasi Kopi Berbasis Web yang bisa dilihat pada gambar dibawah ini.

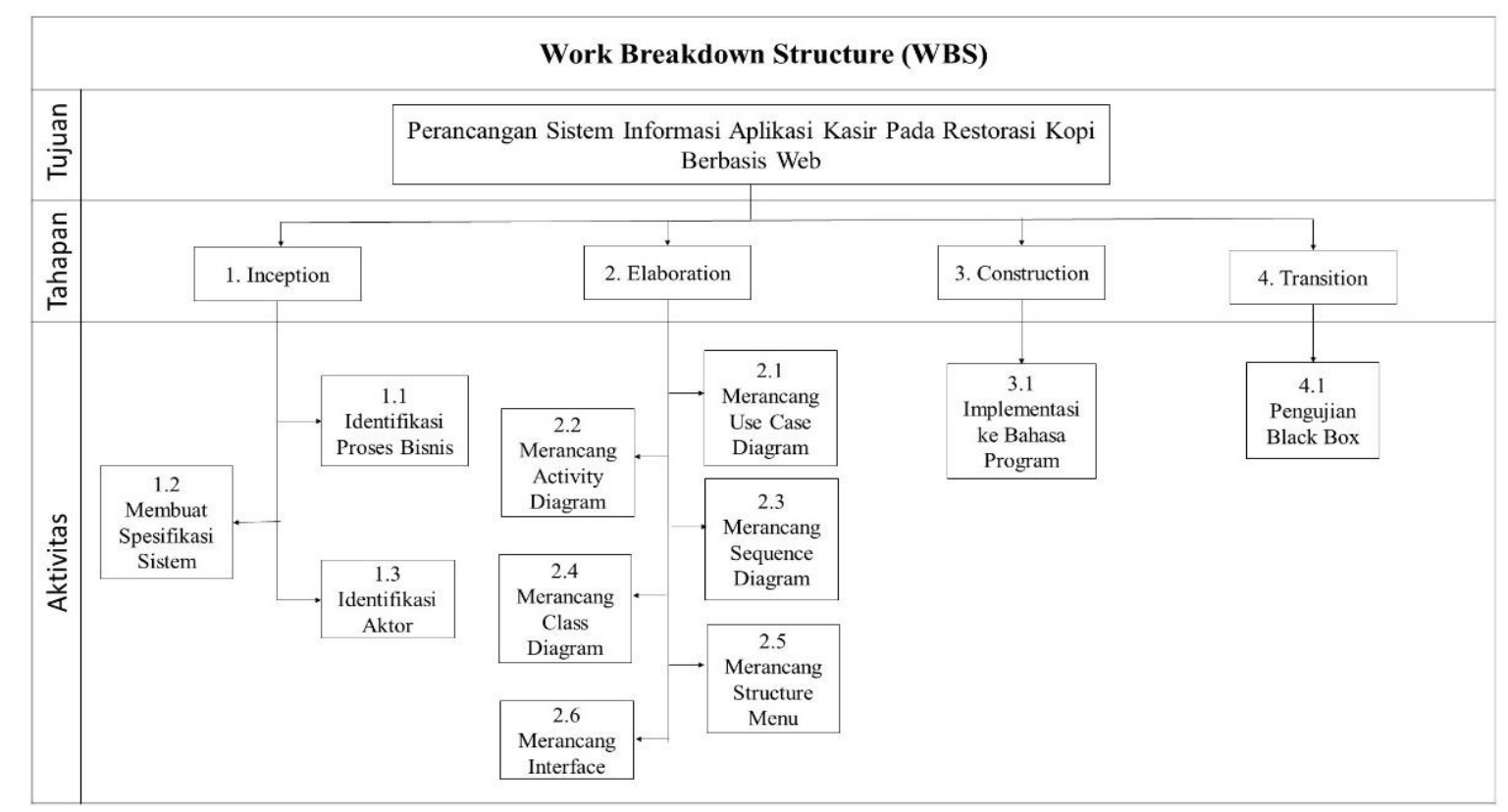

Gambar 1 : Work Breakdown Structure 
Pada tahap inception dilakukan identifikasi proses bisnis, membuat spesifikasi sistem, dan identifikasi actor [10]. Tahapan elaboration menentukan penggambaran awal dengan pemodelan Unified Modeling Language (UML) yang menggunakan diagram use case, diagram activity, diagram sequence, diagram class, struktur menu dan interface. Tahapan ketiga construction untuk implementasi rancangan interface yang telah dibuat sebelumnya kedalam bahasa pemrograman. Pada tahapan terakhir transition dilakukannya pengujian terhadap aplikasi menggunakan black box [11]. Maka menghasilkan uraian rencana aktivitas dan juga waktu pengerjaan penelitian yang dikerjakan.

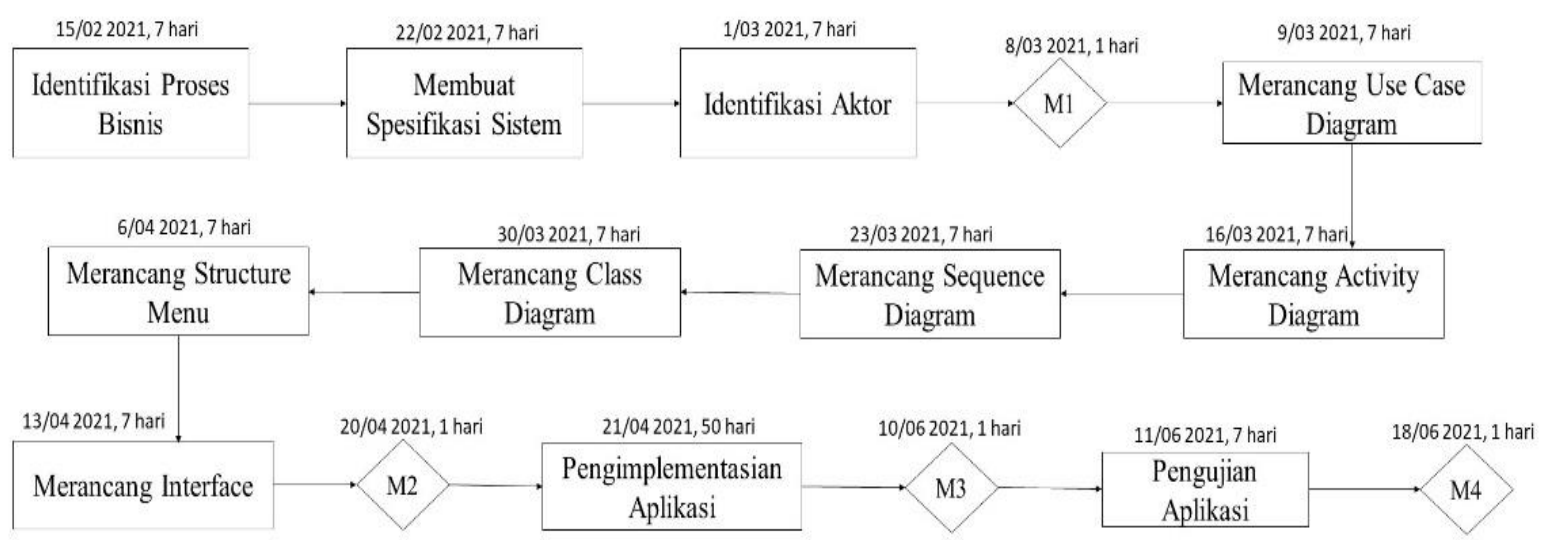

Gambar 2 : Diagram Alur Aktivitas

\section{HASIL DAN PEMBAHASAN}

\section{A. Inception}

Pada tahap pertama ini sebagai persiapan untuk melakukan perancangan sistem aplikasi yang akan dibangun dengan menentukan identifikasi proses bisnis. Maka dibuatkan lah gambaran identifkasi proses bisnis yang akan berjalan pada gambar 3 .

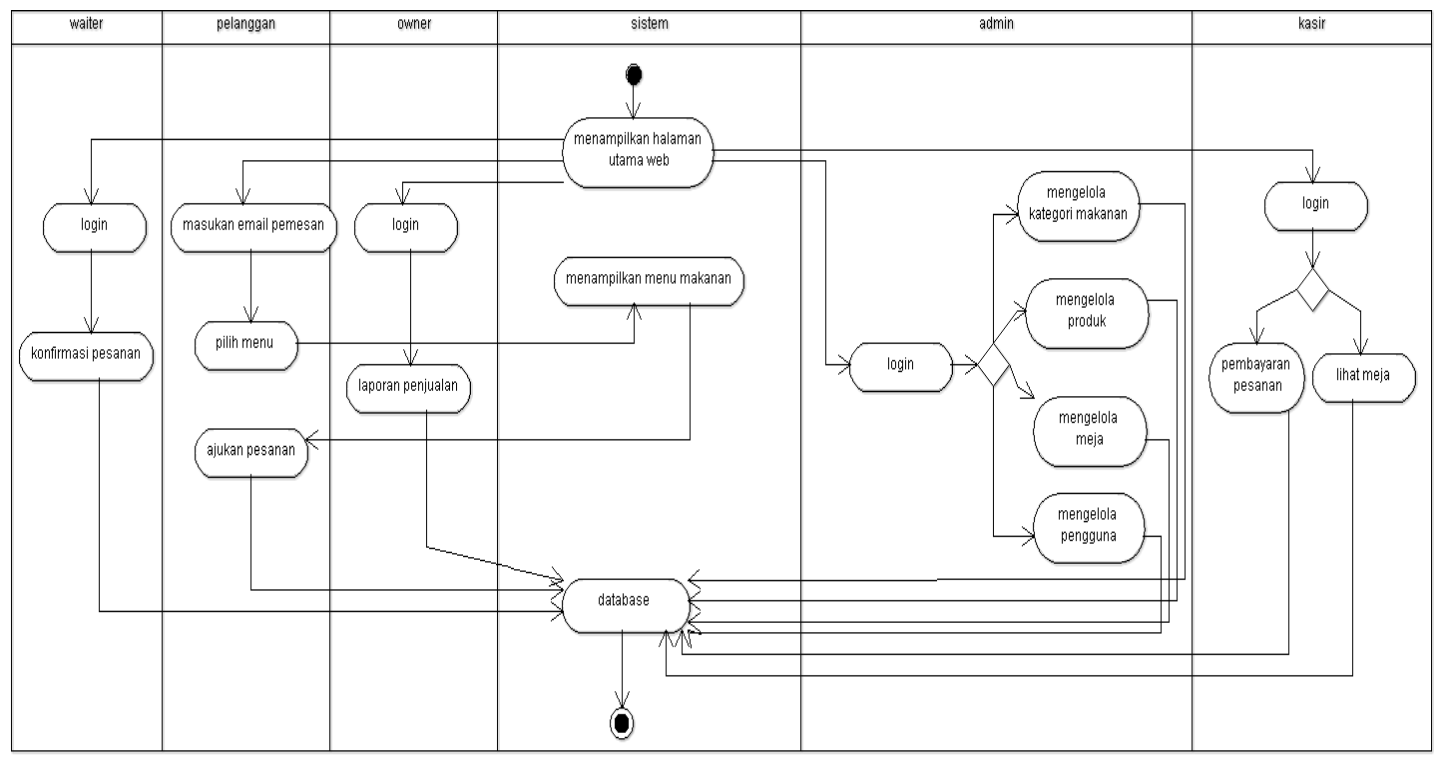

Gambar 3 : Proses Bisnis Restorasi Kopi

Penjelasan dari gambar diatas tentang identifikasi proses bisnis yang akan berjalan dijelaskan pada tabel dibawah ini. 
Tabel 1 : Penjelasan Proses Bisnis

\begin{tabular}{|c|c|c|}
\hline No & Aktivitas & Deskripsi \\
\hline 1 & Login & $\begin{array}{l}\text { Semua user aplikasi harus melakukan login terlebih dahulu } \\
\text { untuk bisa mengakses aplikasinya }\end{array}$ \\
\hline 2 & Konfirmasi pesanan & $\begin{array}{l}\text { User dengan level waiter dapat mengkonfirmasi pesanan } \\
\text { yang dipesan oleh pelanggan }\end{array}$ \\
\hline 3 & Masukan email pemesan & $\begin{array}{l}\text { Pelanggan yang sudah menscan Qr code harus mengisi email } \\
\text { untuk bisa memesan makanan }\end{array}$ \\
\hline 4 & Pilih menu & $\begin{array}{l}\text { Pelanggan memilih menu yang ada di aplikasi sesuai dengan } \\
\text { yang dipilih }\end{array}$ \\
\hline 5 & Ajukan pesanan & $\begin{array}{l}\text { Pelanggan ketika sudah memilih menu klik ajukan pesanan } \\
\text { untuk diproses oleh pekerja kafe }\end{array}$ \\
\hline 6 & Laporan penjualan & User dengan level owner dapat melihat laporan penjualan \\
\hline 7 & $\begin{array}{l}\text { Mengelola kategori } \\
\text { makanan }\end{array}$ & $\begin{array}{l}\text { User dengan level admin dapat mengelola kategori makanan } \\
\text { seperti tambah, edit, dan hapus }\end{array}$ \\
\hline 8 & Mengelola produk & $\begin{array}{l}\text { User dengan level admin dapat mengelola produk makanan } \\
\text { seperti tambah, edit, dan hapus }\end{array}$ \\
\hline 9 & Mengelola meja & $\begin{array}{l}\text { User dengan level admin dapat mengelola meja seperti } \\
\text { tambah meja, lihat Qr code, refresh Qr code, print } \text { Qr code, } \\
\text { ubah status meja, dan hapus meja }\end{array}$ \\
\hline 10 & Mengelola pengguna & $\begin{array}{l}\text { User dengan level admin dapat mengelola pengguna dengan } \\
\text { level-level sesuai role nya }\end{array}$ \\
\hline 11 & Pembayaran pesanan & $\begin{array}{l}\text { User dengan level kasir dapat melakukan pembayaran } \\
\text { pesanan dengan pelanggan sesuai dengan total seluruh dari } \\
\text { harga pesanannya }\end{array}$ \\
\hline 12 & Lihat meja & $\begin{array}{l}\text { User dengan level kasir dapat melihat meja untuk } \\
\text { mengetahui meja mana yang diisi atau tidak }\end{array}$ \\
\hline
\end{tabular}

\section{B. Elaboration}

\section{Diagram Use Case}

Suatu aktivitas dengan bertujuan untuk gambaran fungsi-fungsi yang terdapat di sistem informasi aplikasi kasir pada kafe restorasi kopi dan aktor yang bisa menjalankan beberapa fungsi tersebut [12]. 


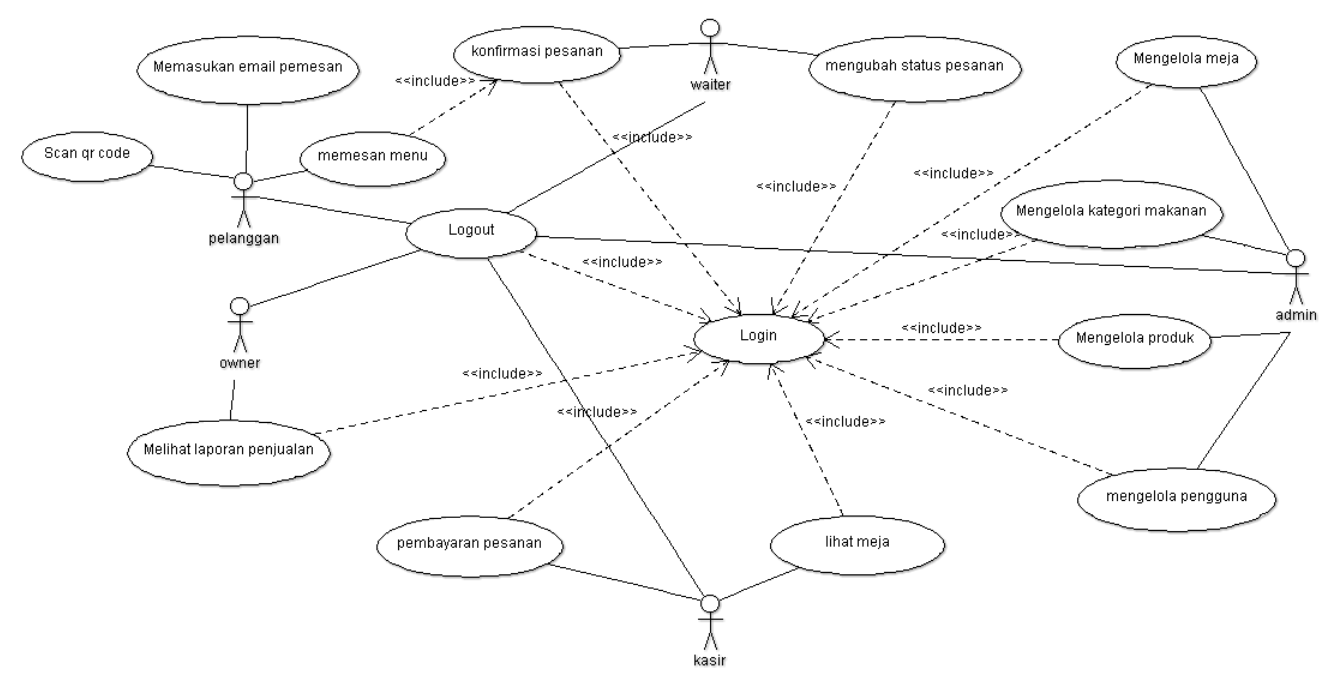

Gambar 4 : Use Case Diagram

\section{Activity Diagram}

Berdasarkan use case diatas maka pada aktivitas ini menghasilkan rancangan acttivity diagram login user untuk menjelaskan aktivitasnya pada Aplikasi Kasir.

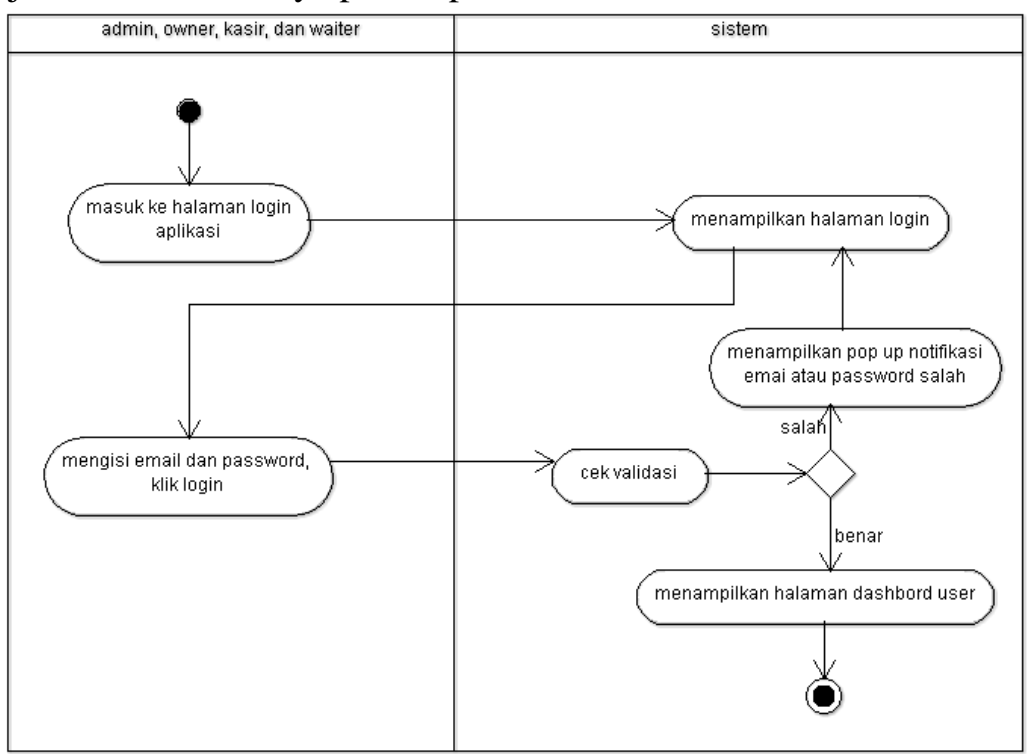

Gambar 5 : Activity Diagram Login

\section{Diagram Sequence}

Gambaran interaksi antara aktor dan sistem, berikut gambar diagram sequence login. 


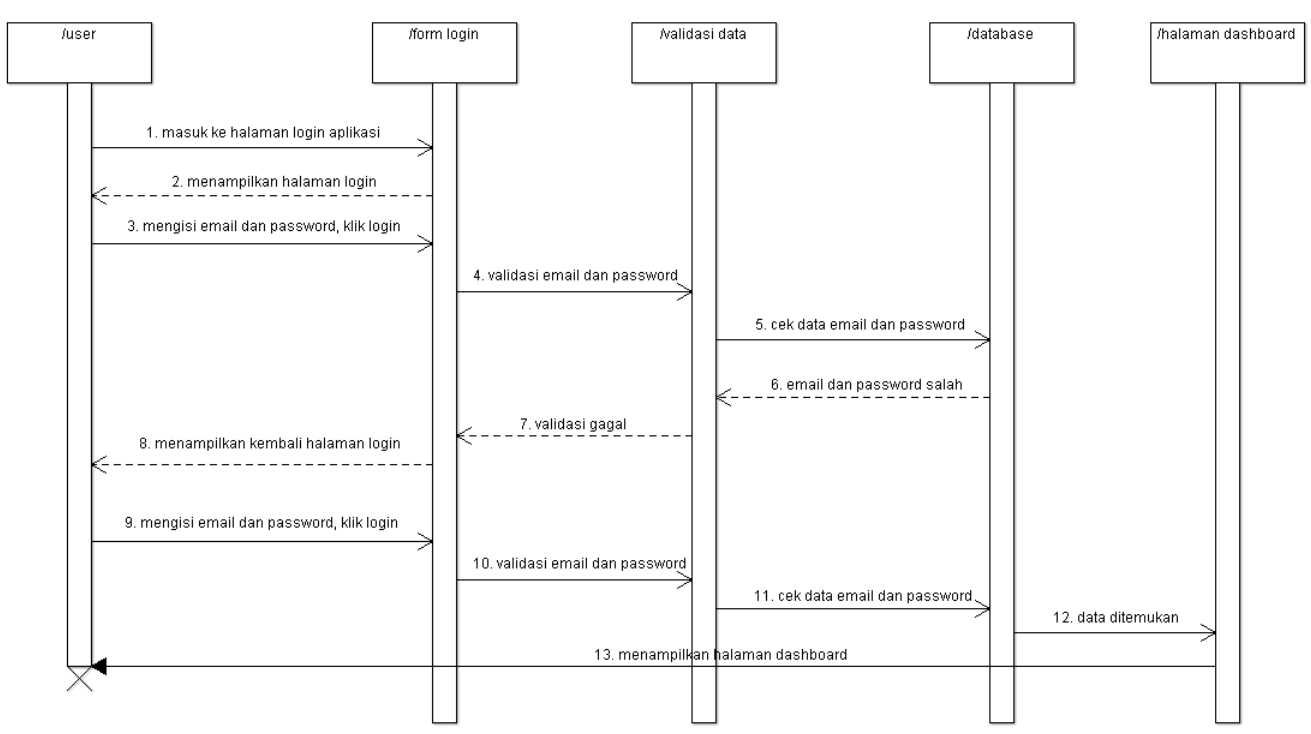

Gambar 6 : Sequence Diagram Login

4. Diagram Class

Bertujuan untuk menjelaskan struktur sistem dari pengelompokan beberapa kelas yang akan dirancang untuk membangun sebuah sistem agar dapat sesuai dengan yang dibutuhkan dan diharapkan.

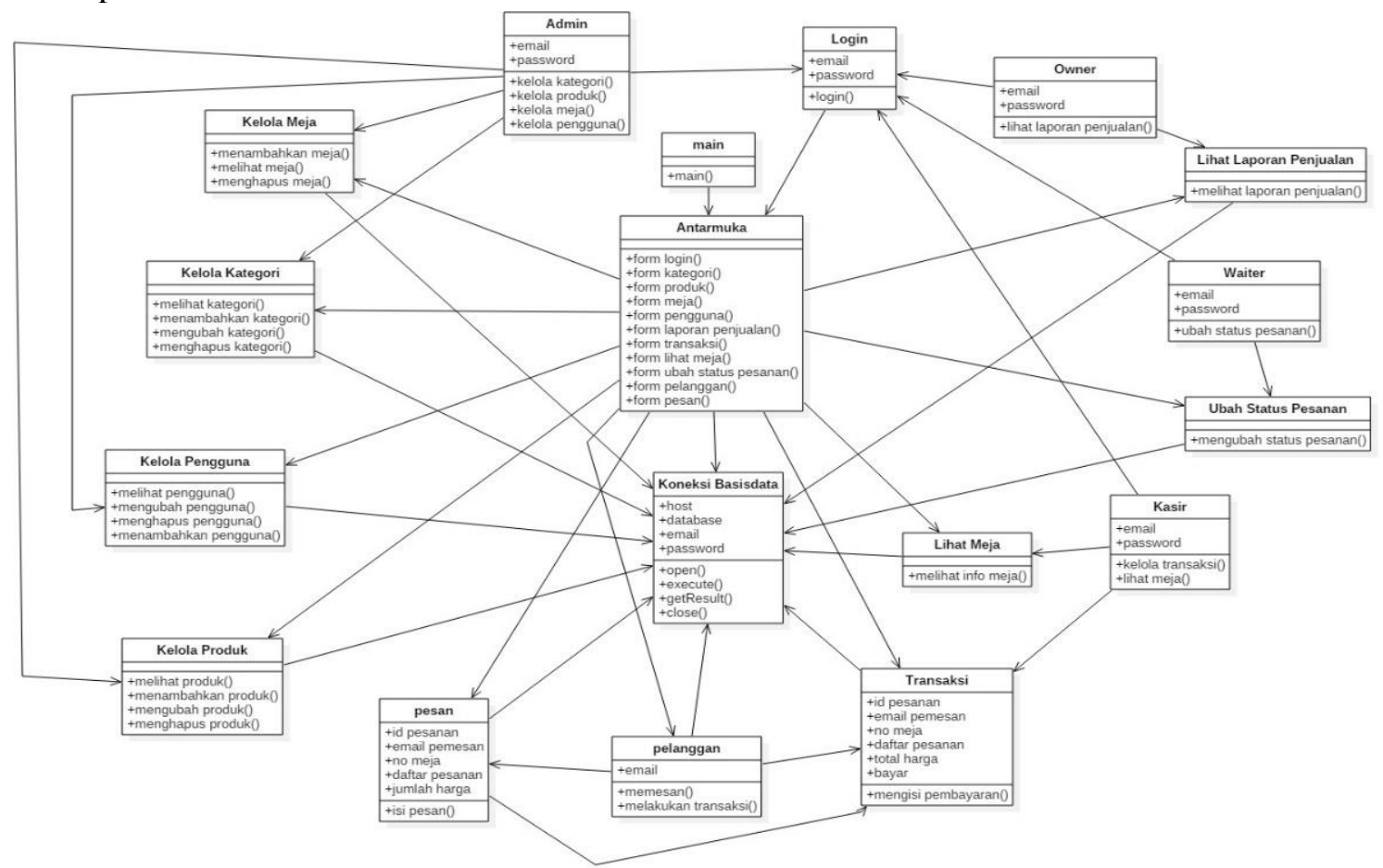

Gambar 7 : Class Diagram

\section{Perancangan Interface}

Perancangan interface merupakan rancangan tampilan atau gambaran sementara yang dipakai untuk perantara antara perangkat lunak dengan user yang akan dibangun. Adapun tampilan interface yang telah dirancang pada gambar dibawah. 


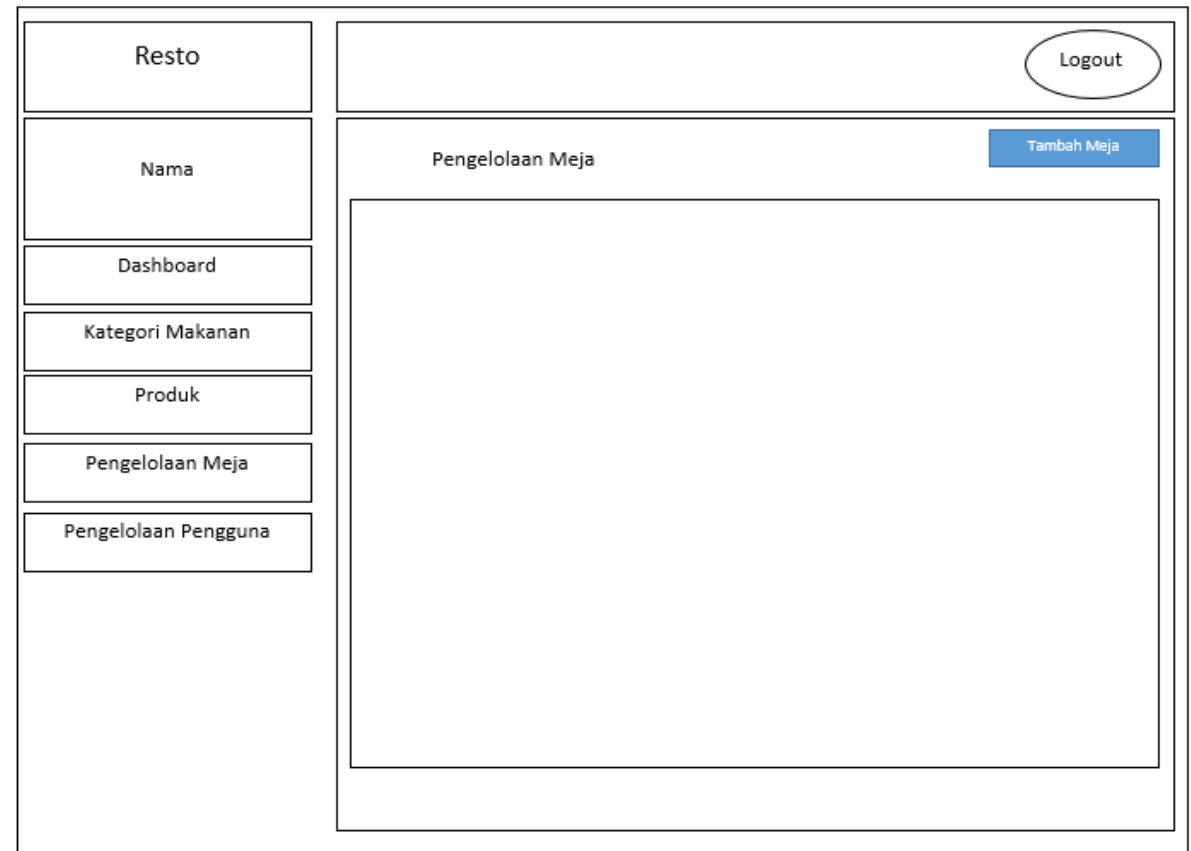

Gambar 8 : Rancangan Pengelolaan Meja

Pada gambar diatas menggambarkan tentang rancangan tampilan sementara halaman pengelola meja.

\section{Construction}

Merupakan tahapan yang bertujuan untuk pengimplementasian rancangan interface yang telah dibuat sebelumnya kedalam bahasa pemrograman.

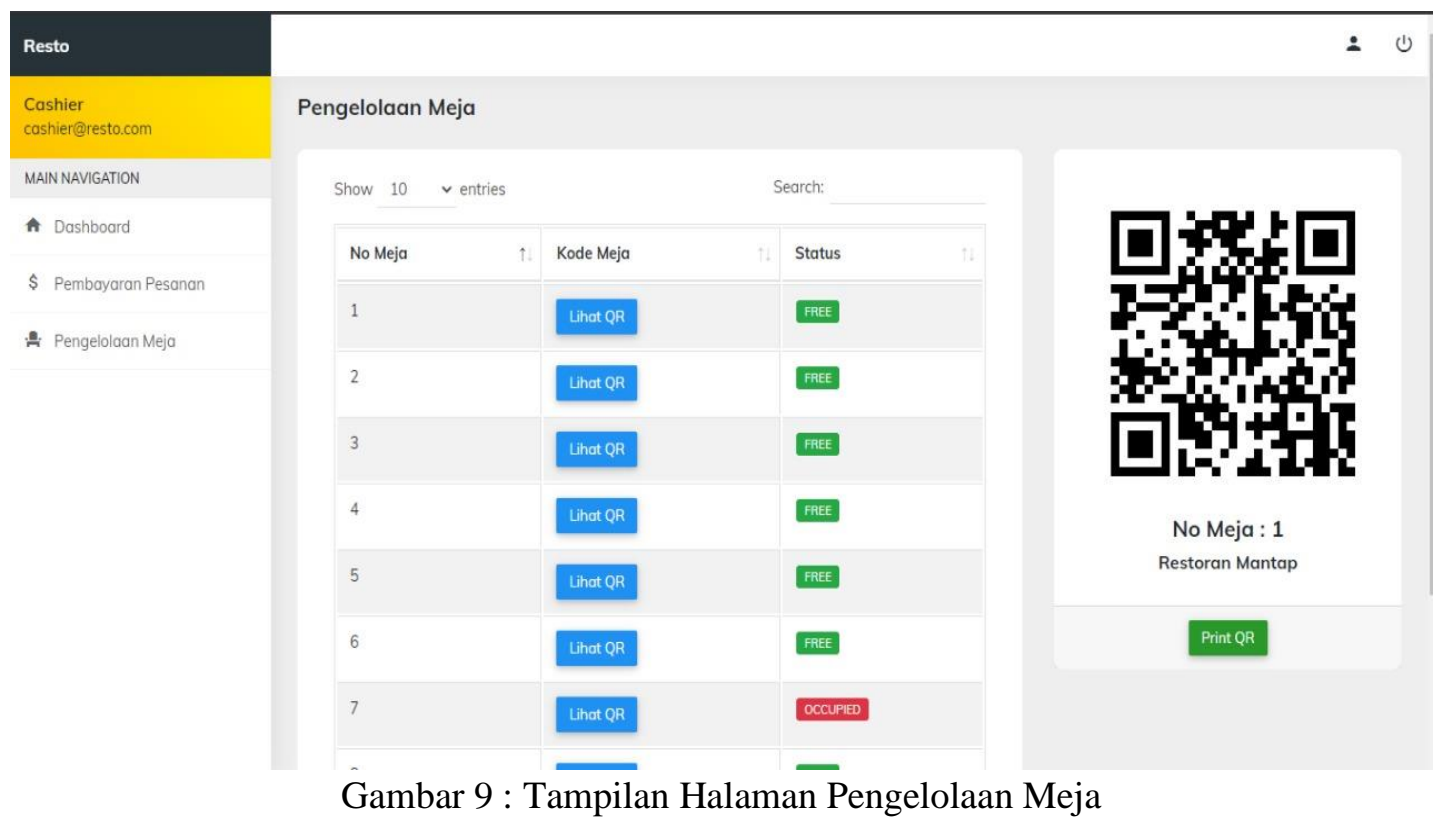

Gambar diatas merupakan tampilan pengelolaan meja aplikasi bagi admin agar bisa mengelola meja di café dan mencetak qr code. 


\section{Transition}

Tahapan terakhir dilakukannya pengujian kepada aplikasi yang telah dirancang, untuk tahapan pengujian ini menggunakan black box yang mana pengujiannya dilakukan kepada fitur-fitur yang terdapat pada aplikasi.

Tabel 2 : Pengujian Black box

\begin{tabular}{|c|c|c|c|c|c|}
\hline No & Aktivitas & Uji Coba & $\begin{array}{l}\text { Skenario } \\
\text { Uji Coba } \\
\end{array}$ & $\begin{array}{c}\begin{array}{c}\text { Keluaran yang } \\
\text { diharapkan }\end{array} \\
\end{array}$ & Keterangan \\
\hline \multirow[t]{2}{*}{1} & Login & $\begin{array}{l}\text { login dengan } \\
\text { tepat }\end{array}$ & $\begin{array}{l}\text { Memasukan email } \\
\& \text { password yang } \\
\text { tepat }\end{array}$ & $\begin{array}{l}\text { Login berhasil dan masuk } \\
\text { halaman dashboard }\end{array}$ & Sukses \\
\hline & & $\begin{array}{l}\text { Melakukan } \\
\text { login dengan } \\
\text { salah }\end{array}$ & $\begin{array}{l}\text { Memasukan email } \\
\text { \& password salah }\end{array}$ & $\begin{array}{l}\text { Login tidak berhasil maka } \\
\text { kembali ke halaman login }\end{array}$ & Sukses \\
\hline 2 & Logout & $\begin{array}{l}\text { Melakukan } \\
\text { logout }\end{array}$ & $\begin{array}{l}\text { Mengklik tombol } \\
\text { logout }\end{array}$ & Logout berhasil & Sukses \\
\hline \multirow[t]{4}{*}{3} & $\begin{array}{l}\text { Memesan } \\
\text { menu }\end{array}$ & $\begin{array}{l}\text { Memasukan } \\
\text { email pemesan }\end{array}$ & $\begin{array}{l}\text { Mengisi email } \\
\text { pemesan dengan } \\
\text { format benar }\end{array}$ & $\begin{array}{l}\text { Berhasil dan masuk } \\
\text { halaman menu makanan }\end{array}$ & Sukses \\
\hline & & & $\begin{array}{l}\text { Email pemesan } \\
\text { dengan format } \\
\text { salah }\end{array}$ & $\begin{array}{l}\text { Gagal dan kembali ke } \\
\text { form isian email }\end{array}$ & Sukses \\
\hline & & Memilih menu & $\begin{array}{l}\text { Mengklik menu } \\
\text { yang dipilih }\end{array}$ & $\begin{array}{l}\text { Masuk ke daftar pesanan } \\
\text { yang dipilih }\end{array}$ & Sukses \\
\hline & & Ajukan pesanan & $\begin{array}{l}\text { Mengklik ajukan } \\
\text { pesanan }\end{array}$ & $\begin{array}{l}\text { Muncul ke konfirmasi } \\
\text { pesanan di waiter }\end{array}$ & Sukses \\
\hline \multirow[t]{3}{*}{4} & $\begin{array}{l}\text { Konfirmasi } \\
\text { pesanan }\end{array}$ & $\begin{array}{l}\text { Menerima } \\
\text { pesanan }\end{array}$ & $\begin{array}{l}\text { Mengklik ubah } \\
\text { status pesanan } \\
\text { menjadi diterima }\end{array}$ & $\begin{array}{l}\text { Status pesanan berubah } \\
\text { menjadi diterima }\end{array}$ & Sukses \\
\hline & & $\begin{array}{l}\text { Mengantar } \\
\text { pesanan }\end{array}$ & $\begin{array}{l}\text { Mengklik ubah } \\
\text { status pesanan } \\
\text { menjadi diantar } \\
\end{array}$ & $\begin{array}{l}\text { Status pesanan berubah } \\
\text { menjadi diantar }\end{array}$ & Sukses \\
\hline & & $\begin{array}{l}\text { Menolak } \\
\text { pesanan }\end{array}$ & $\begin{array}{l}\text { Mengklik ubah } \\
\text { status pesanan } \\
\text { menjadi ditolak }\end{array}$ & $\begin{array}{l}\text { Status pesanan berubah } \\
\text { menjadi ditolak }\end{array}$ & Sukses \\
\hline \multirow[t]{5}{*}{5} & $\begin{array}{l}\text { Mengelola } \\
\text { kategori }\end{array}$ & $\begin{array}{l}\text { Menambahkan } \\
\text { kategori }\end{array}$ & $\begin{array}{l}\text { Memasukan } \\
\text { kategori dengan } \\
\text { aturan yang benar }\end{array}$ & $\begin{array}{l}\text { Kategori disimpan ke } \\
\text { database dan muncul } \\
\text { pemberitahuan berhasil }\end{array}$ & Sukses \\
\hline & & & $\begin{array}{l}\text { Memasukan } \\
\text { kategori dengan } \\
\text { aturan yang salah }\end{array}$ & $\begin{array}{l}\text { Muncul pemberitahuan } \\
\text { gagal }\end{array}$ & Sukses \\
\hline & & $\begin{array}{l}\text { Mengedit } \\
\text { kategori }\end{array}$ & $\begin{array}{l}\text { Mengubah } \\
\text { kategori dengan } \\
\text { aturan yang benar }\end{array}$ & $\begin{array}{l}\text { Kategori dalam database } \\
\text { diperbaharui dan muncul } \\
\text { pemberitahuan berhasil }\end{array}$ & Sukses \\
\hline & & & $\begin{array}{l}\text { Mengubah } \\
\text { kategori dengan } \\
\text { aturan yang salah }\end{array}$ & $\begin{array}{l}\text { Muncul pemberitahuan } \\
\text { gagal }\end{array}$ & Sukses \\
\hline & & $\begin{array}{l}\text { Menghapus } \\
\text { kategori }\end{array}$ & $\begin{array}{l}\text { Menghapus } \\
\text { kategori dengan } \\
\text { klik ya }\end{array}$ & Kategori berhasil dihapus & Sukses \\
\hline
\end{tabular}




\begin{tabular}{|c|c|c|c|c|c|}
\hline No & Aktivitas & Uji Coba & $\begin{array}{l}\text { Skenario } \\
\text { Uji Coba } \\
\end{array}$ & $\begin{array}{c}\text { Keluaran yang } \\
\text { diharapkan }\end{array}$ & Keterangan \\
\hline & & & $\begin{array}{l}\text { kategori dengan } \\
\text { klik tidak }\end{array}$ & & \\
\hline \multirow[t]{6}{*}{6} & $\begin{array}{l}\text { Mengelola } \\
\text { produk }\end{array}$ & $\begin{array}{l}\text { Menambahkan } \\
\text { produk }\end{array}$ & $\begin{array}{l}\text { Memasukan } \\
\text { produk dengan } \\
\text { aturan yang benar }\end{array}$ & $\begin{array}{l}\text { Produk disimpan ke } \\
\text { database dan muncul } \\
\text { pemberitahuan berhasil }\end{array}$ & Sukses \\
\hline & & & $\begin{array}{l}\text { Memasukan } \\
\text { produk dengan } \\
\text { aturan yang salah }\end{array}$ & $\begin{array}{l}\text { Muncul pemberitahuan } \\
\text { gagal }\end{array}$ & Sukses \\
\hline & & $\begin{array}{l}\text { Mengedit } \\
\text { produk }\end{array}$ & $\begin{array}{l}\text { Mengubah produk } \\
\text { dengan aturan } \\
\text { yang benar }\end{array}$ & $\begin{array}{l}\text { Produk dalam database } \\
\text { diperbaharui dan muncul } \\
\text { pemberitahuan berhasil }\end{array}$ & Sukses \\
\hline & & & $\begin{array}{l}\text { Memasukan } \\
\text { produk dengan } \\
\text { aturan yang salah }\end{array}$ & $\begin{array}{l}\text { Muncul pemberitahuan } \\
\text { gagal }\end{array}$ & Sukses \\
\hline & & $\begin{array}{l}\text { Menghapus } \\
\text { produk }\end{array}$ & $\begin{array}{l}\text { Menghapus } \\
\text { produk dengan } \\
\text { klik ya }\end{array}$ & Produk berhasil dihapus & Sukses \\
\hline & & & $\begin{array}{l}\text { Menghapus } \\
\text { produk dengan } \\
\text { klik tidak }\end{array}$ & Produk tidak terhapus & Sukses \\
\hline \multirow[t]{6}{*}{7} & $\begin{array}{l}\text { Mengelola } \\
\text { meja }\end{array}$ & $\begin{array}{l}\text { Menambahkan } \\
\text { meja }\end{array}$ & $\begin{array}{l}\text { Memasukan } \\
\text { aturan meja } \\
\text { dengan benar }\end{array}$ & $\begin{array}{l}\text { Meja berhasil } \\
\text { ditambahkan }\end{array}$ & Sukses \\
\hline & & & $\begin{array}{l}\text { Memasukan } \\
\text { aturan meja } \\
\text { dengan salah }\end{array}$ & $\begin{array}{l}\text { Meja tidak berhasil } \\
\text { ditambahkan }\end{array}$ & Sukses \\
\hline & & $\begin{array}{l}\text { Mengubah } \\
\text { status meja }\end{array}$ & $\begin{array}{l}\text { Meja sedang } \\
\text { digunakan }\end{array}$ & Muncul status terpakai & Sukses \\
\hline & & & $\begin{array}{l}\text { Meja tidak } \\
\text { digunakan }\end{array}$ & Muncul status free & Sukses \\
\hline & & Qr code & $\begin{array}{l}\text { Melihat } q r \text { code } \\
\text { dengan klik lihat }\end{array}$ & Menampilkan $q r$ code & Sukses \\
\hline & & & $\begin{array}{l}\text { Refresh qr code } \\
\text { dengan klik } \\
\text { refresh }\end{array}$ & $\begin{array}{l}\text { Qr code berubah dari } \\
\text { sebelumnya }\end{array}$ & Sukses \\
\hline \multirow[t]{2}{*}{8} & $\begin{array}{l}\text { Mengelola } \\
\text { pengguna }\end{array}$ & $\begin{array}{l}\text { Menambahkan } \\
\text { pengguna }\end{array}$ & $\begin{array}{l}\text { Memasukan } \\
\text { pengguna dengan } \\
\text { aturan yang benar }\end{array}$ & $\begin{array}{l}\text { Pengguna berhasil } \\
\text { ditambahkan }\end{array}$ & Sukses \\
\hline & & & $\begin{array}{l}\text { Memasukan } \\
\text { pengguna dengan } \\
\text { aturan yang salah }\end{array}$ & $\begin{array}{l}\text { Muncul pemberitahuan } \\
\text { gagal }\end{array}$ & Sukses \\
\hline \multirow[t]{2}{*}{9} & $\begin{array}{l}\text { Melihat } \\
\text { laporan } \\
\text { penjualan }\end{array}$ & $\begin{array}{l}\text { Mencari laporan } \\
\text { penjualan }\end{array}$ & $\begin{array}{l}\text { Memasukan kata } \\
\text { kunci yang sesuai }\end{array}$ & $\begin{array}{l}\text { Menampilkan data } \\
\text { laporan penjualan sesuai } \\
\text { dengan kata kunci }\end{array}$ & Sukses \\
\hline & & & $\begin{array}{l}\text { Memasukan kata } \\
\text { kunci tidak sesuai }\end{array}$ & $\begin{array}{l}\text { Muncul pemberitahuan } \\
\text { gagal }\end{array}$ & Sukses \\
\hline 10 & $\begin{array}{l}\text { Status } \\
\text { pembayaran }\end{array}$ & $\begin{array}{l}\text { Menghitung } \\
\text { total pesanan }\end{array}$ & $\begin{array}{l}\text { Memasukan } \\
\text { nominal } \\
\text { pembayaran tidak } \\
\text { kurang dari total } \\
\text { pesanan }\end{array}$ & $\begin{array}{l}\text { Menampilkan total } \\
\text { kembalian dengan sesuai }\end{array}$ & Sukses \\
\hline
\end{tabular}




\begin{tabular}{|c|c|c|c|c|c|}
\hline No & Aktivitas & Uji Coba & $\begin{array}{l}\text { Skenario } \\
\text { Uji Coba }\end{array}$ & $\begin{array}{c}\text { Keluaran yang } \\
\text { diharapkan }\end{array}$ & Keterangan \\
\hline & & & $\begin{array}{l}\text { Memasukan } \\
\text { nominal } \\
\text { pembayaran } \\
\text { kurang dari total } \\
\text { pesanan }\end{array}$ & $\begin{array}{l}\text { Tidak menampilkan total } \\
\text { kembalian }\end{array}$ & Sukses \\
\hline & & $\begin{array}{l}\text { Membatalkan } \\
\text { pesanan pada } \\
\text { struk } \\
\text { pembayaran }\end{array}$ & $\begin{array}{l}\text { Mengklik tombol } \\
\mathrm{x} \text { di pesanan yang } \\
\text { tidak datang }\end{array}$ & $\begin{array}{l}\text { Terhapus dari daftar } \\
\text { pesanan pembayaran }\end{array}$ & Sukses \\
\hline & & $\begin{array}{l}\text { Mencetak struk } \\
\text { pembayaran }\end{array}$ & $\begin{array}{l}\text { Mengklik tombol } \\
\text { cetak }\end{array}$ & $\begin{array}{l}\text { Mencetak struk } \\
\text { pembayaran }\end{array}$ & Sukses \\
\hline & Lihat meja & Melihat meja & $\begin{array}{l}\text { Mengklik tombol } \\
\text { lihat meja }\end{array}$ & $\begin{array}{l}\text { Menampilkan informasi } \\
\text { meja }\end{array}$ & Sukses \\
\hline
\end{tabular}

\section{KESIMPULAN DAN SARAN}

\section{A. Kesimpulan}

Berdasarkan hasil survei yang dilakukan dalam penelitian ini, maka dapat disimpulkan bahwa aplikasi yang telah dirancang dapat mempermudah proses pemesanan menu dan dapat diakses melalui smartphone pribadi pelanggan dengan menggunakan scan $q r$ code. Pada aplikasi ini, tampilan menu makanan menjadi lebih menarik dengan menggunakan gambar dan deskripsi menu serta dapat mempermudah proses transaksi antara pelanggan dan pihak kafe tersebut. Dengan adanya fitur laporan penjualan, pemilik usaha akan lebih mudah mengetahui laporan penjualan setiap harinya. Maka aplikasi ini tentu bermanfaat untuk meningkatkan kualitas kafe tersebut secara terkomputerisasi, sehingga dapat meminimalisir kesalahan human error.

\section{B. Saran}

Adapun saran untuk membuat aplikasi ini menjadi lebih baik kedepannya yaitu menambahkan video pada tampilan menu makanan sehingga dapat menjadikan tampilan menu lebih indah, menambahkan fitur kirim struk pembayaran secara langsung mengirimkannya ke email pemesan.

\section{DAFTAR PUSTAKA}

[1] S. Febrina and S. Hanggowidjaja, "Perancangan Interior Café Playground di Surabaya," vol. 7, no. 2, pp. 211-217, 2019.

[2] N. Rubiati and S. W. Harahap, "Aplikasi Absensi Siswa Menggunakan Qr Code Dengan Bahasa Pemrograman Php Di Smkit Zunurain Aqila Zahra Di Pelintung," I N F O R M a T I Ka, vol. 11, no. 1, p. 62, 2019, doi: 10.36723/juri.v11i1.156.

[3] Suharianto, L. B. A. Pambudi, A. Rahagiyanto, and G. E. J. Suyoso, "Implementasi QR Code untuk Efisiensi Waktu Pemesanan Menu Makanan dan Minuman di Restoran maupun Kafe," BIOS J. Teknol. Inf. dan Rekayasa Komput., vol. 1, no. 1, pp. 35-39, 2020, doi: 10.37148/bios.v1i1.7.

[4] S. Rahayu, A. Muthohari, and Bunyamin, "PENGEMBANGAN APLIKASI KASIR PADA SISTEM INFORMASI RUMAH MAKAN PADANG ARIUNG | Jurnal Algoritma,” pp. 157-163, 2013.

[5] K. Widianto, Rismaniah, and T. Setiyorini, "Sistem Informasi Penjualan Makanan Dan Minuman Di Wejie Kopi Berbasis Web," vol. 5, no. 1, pp. 55-66, 2020.

[6] G. W. W and R. Rachmatullah, "Sistem Informasi Kasir di Hokky Waroeng Dimsum Surakarta," Indones. J. Netw. Secur., vol. 5, no. 4, p. 77, 2016.

[7] M. T. Setiawan, T. Yogaswara, and N. Meliana, "SISTEM INFORMASI KASIR BERBASIS WEB 
PADA B-FOOD BUMIAYU," vol. 6, no. 2, pp. 134-142, 2020.

[8] N. Setiadi and R. Setiawan, "Pengembangan Aplikasi Penjualan Sparepart di Bengkel Anugrah Jaya Motor Berbasis Desktop," J. Algoritm., vol. 13, no. 2, pp. 399-406, 2017, doi: 10.33364/algoritma/v.132.399 .

[9] R. A. Sukamto and M. Shalahuddin, Rekayasa Perangkat Lunak Terstruktur dan Berorientasi Objek. Informatika-Bandung, 2018.

[10] D. J. Hutahaean, N. H. Wardani, and W. Purnomo, "Pengembangan Sistem Informasi Penyewaan Gedung Berbasis Web dengan Metode Rational Unified Process (RUP) (Studi Kasus: Wisma Rata Medan)," J. Pengemb. Teknol. Inf. dan Ilmu Komput., vol. 3, no. Vol. 3, No. 6, Juni, pp. 5789-5798, 2019.

[11] A. U. Hamdani and M. A. Fk, "Pemodelan Sistem Informasi Administrasi Pendistribusian Kartu Asuransi Akda Extra Studi Kasus : PT. Asuransi Bhakti Bhayangkara Jakarta,” Int. J. ISSN 2089-9815, vol. 2015, no. Sentika, pp. 245-252, 2015.

[12] M. I. Juwita, S. A. Wicaksono, and N. Y. Setiawan, "Pengembangan Sistem Informasi Tracer Study Alumni Berbasis Web Menggunakan Metode RUP ( Studi Kasus : SMA Suluh Jakarta Selatan )," J. Pengemb. Tenknologi Inf. dan Ilmu Komput., vol. 3, no. 6, pp. 5703-5710, 2019, [Online]. Available: http://repository.ub.ac.id/172009/. 